\title{
CREATING A LIVING LAB MODEL FOR TOURISM AND HOSPITALITY BUSINESSES TO STIMULATE CSR AND SUSTAINABILITY INNOVATIONS
}

\author{
KARIYE CIGIR ${ }^{1,2}$ \\ ${ }^{1}$ Juraj Dobrila University of Pula, Croatia \\ ${ }^{2} \mathrm{FH}$ Burgenland, Eisenstadt, Austria
}

\begin{abstract}
Living Lab is a user centred open-innovation research concept and environment that integrates concurrent research and innovation processes. The innovation capacity of living labs is discussed in academia mainly in sectors like Information and Communication Technologies (ICT), Smart Cities, and Social Innovation. In travel and tourism, living labs so far are analysed in regard to destination management to boost the attractiveness of rural areas and agri-tourism activities in countries like Bulgaria and Canada. This paper aims to apply the living labs method in the context of sustainable and responsible tourism. Therefore this study concentrates on model creation, mainly of living labs in tourism in general, and then zooms in to the application of living labs in the particular case of a leisure resort and hotel. By visualizing different models of living lab implementation, these findings can contribute to a pragmatic approach to promote the understanding of the living lab environment and its methodology and the elegant implementation of living labs in general. Two key elements of living labs in the hospitality business, firstly the embedded CSR supply chain for co-creation and partner involvement and secondly engaging hotel guests in user involvement, will be highlighted in order to show the potential and capability of living lab development for creating and maintaining sustainable tourism innovations.
\end{abstract}

Keywords: living lab, stimulating innovation capability, corporate social responsibility (CSR), sustainability, hospitality, model development, model creation.

\section{INTRODUCTION}

The tourism sector is growing and developing like other industries and needs innovation for its growth. Tourism researchers have discovered innovation methods and defined innovation environments like living labs (LL) [1], [2] and call for research on living labs [3]. The benefits for open innovation approaches besides cost saving are user value improvement or network value [4], and better innovation performance [5]. The importance of different roles of participants within LL and the definition of these roles help to understand their construction, utilization and orchestration [6]. In this paper, the author illustrates the network and all LL participants, and users as innovators which are in the centre of innovations, whether for incremental or for radical innovations. To comb this terrain, some insights about existing and already performed living labs are given and their main scientific contributions are analysed and summarized before presenting the authors' own models.

Research interest in LL rises rapidly. Developed by MIT professor William Mitchell [7] LL are used to refer to a purpose-built lab where the routine activities of everyday life can be observed, recorded for later analysis and then can be experimentally manipulated by changing e.g. input variables. For practical implementation, The European Network of Living Labs (ENoLL) disposes over the international federation of benchmarked Living Labs in Europe and worldwide. "...ENoLL provides co-creation, user engagement, test and experimentation facilities targeting innovation in many different domains such as energy, media, mobility, healthcare, agrifood, etc., to act as a platform for best practice exchange, learning and support, and Living Lab international project development" [8]. 
The analysis of publications in academic literature by searching "Sciencedirect.com" resulted in 3,117 papers with the search term "Living Lab", published only this year until March 2018. This number will grow to approximately 8,000 publications until year end. In 2009 there were only 2,285 publications compared to 5,552 in 2017. The increase of interest for the field "Living Lab Tourism" shows a similar development but on a different scale: 2009 saw 36 publications in comparison to 115 in 2017, which means an increase of $319 \%$. When comparing the search result for the string term "Living Lab Hospitality" only 6 articles published in 2009 but 20 scientific papers published in 2017. These figures indicate that tourism is lagging behind other industries in this regard and thus demonstrate the need for research in tourism and hospitality for this relatively new methodology of an open-innovation process.

Taking into account the increased awareness about LL and the interest for LL research, there are milestones set by describing their physical and virtual environment [9], by defining main components and principles [3] and assigning user-roles [10]. Some methods are modelled in living labs, especially in ICT sector [11].

\subsection{What is innovation?}

Schumpeter's most enduring legacy stems from a six-page chapter in "Capitalism, Socialism, and Democracy" entitled "The Process of Creative Destruction". "The same process of industrial mutation - if I may use that biological term - that incessantly revolutionizes the economic structure from within, incessantly destroying the old one, incessantly creating a new one. This process of creative destruction is the essential fact about capitalism" [12]. This was a penetrating and unique insight about how economies grow. Schumpeter explained that economic progress is not gradual and peaceful but rather disjointed and sometimes unpleasant. "Whenever an entrepreneur disrupts an existing industry, it is likely that existing workers, businesses or even entire sectors can be temporarily thrown into loss. These cycles are tolerated, because it allows resources to be freed up for other, more productive uses" [12]. Innovation, moreover, does not only involve creating and disseminating new technologies. It can also consist of initiating far-reaching social and lifestyle changes that may be different from the mainstream but more adapted to society's needs [13]. Furthermore economic and social considerations influence the degree and scale of change [14].

\subsection{What is a Living Lab?}

"A Living Lab is a multi-stakeholder organization set-up to carry out innovation projects that follow the principles of open and user innovation and focus on real-life experimentation" [14]. Mabrouki et al. [15] define a LL as a research methodology for innovation that

Table 1: LL research quantity 2009-2017. (Source: Sciencedirect, 22 Apr. 2018.)

\begin{tabular}{|l|c|c|c|c|c|c|c|c|c|}
\hline Year & 2009 & 2010 & 2011 & 2012 & 2013 & 2014 & 2015 & 2016 & 2017 \\
\hline $\begin{array}{l}\text { No. of } \\
\text { publications }\end{array}$ & 2285 & 2445 & 2820 & 3108 & 3518 & 3824 & 4261 & 4686 & 5552 \\
\hline LL & 2285 & 2445 & 2820 & 3108 & 3518 & 3824 & 4261 & 4686 & 5552 \\
\hline LL tourism & 36 & 29 & 42 & 46 & 53 & 70 & 68 & 96 & 115 \\
\hline $\begin{array}{l}\text { LL } \\
\text { hospitality }\end{array}$ & 6 & 7 & 12 & 14 & 17 & 18 & 21 & 18 & 20 \\
\hline
\end{tabular}


challenges the whole research and innovation process under real-life conditions including human, social, cultural, organizational and institutional aspects. These have an impact on sustainable service, business and technology development. LL is a place for innovation and exploring new possibilities where reflection and evaluation are built into the working progress [16].

One of the answers to the suitability of innovation labs like a LL to foster CSR and sustainability is that LL is a proven means to particularly spur sustainability innovations. Amongst the benefits of co-creation are values such as (1) the better grasp on environmental, social, and economic needs, and (2) a lower risk of failure in product and service design with shorter lead times for new products and services, and (3) higher profits [17]. Another meaningful outcome of LL is the field research that allows participatory observation to identify gaps and potentials. Capacities can be identified through the shift from individuals to communities, from fixed to dynamic needs and contexts, and from personal deficits to shared strengths and opportunities [18]. Thus new perspectives and additional, value added and state-of-the-art answers to dynamic and changing needs can be offered.

The main contribution of this paper is the creation of models of living labs on the macro level and mezzo level for better visualisation and access to the LL as a system, and to illustrate the embedding of elements into a LL on a systemic level. For one element of the travel and tourism businesses on the micro-level, a resort hotel (Fig. 4), a LL model with its sub-elements is developed. Neither in the living labs of other industries nor in the academic papers dealing with tourism destinations, interdependencies' models are available; [1] even point out the lack of territorial borders associated with the areas of intervention in the living lab. Through network models (Figs 5 and 6) the author illustrates different levels of interaction and the simultaneity of actors being in the macro and mezzo level or in the mezzo and micro level at the same time. With this model the complexity of the environment and also the difficulties that may arise by adopting the model in real-life contexts, can be shown. In order to discover new opportunities by leveraging the knowledge and ingenuity of all LL participants, the methods, tools and ideas of living labs must be communicated clearly to all stakeholders for them to implement them in real-life and act on them.

\section{METHODOLOGY}

One qualitative approach used in this study is analysing the scientific literature in regard to the definitions, principles, key components, user roles and macro, meso and micro levels and important milestones of LL. By this method gaps in existing literature are ascertained. Another qualitative approach scrutinizes already developed models, e.g. the key component model [3] and adds to them, especially in tourism and hospitality. The main contribution based on a qualitative methodology is a creation of a network model, which incorporates among others interdependencies and interactions of all relevant stakeholders. A quantitative comparison of publication about living labs in general, living labs in tourism and living labs in hospitality is conducted already at the beginning.

\subsection{Research goal}

This study wants to close some of the gaps in the current academic literature. It focuses on a pragmatic approach. The author will attempt to close some of them, which is more often than not asked by academics. In order to involve the customer into the co-creation process, action research is appropriate. A detailed descriptive grid, which merges different levels of innovation, is generated. This study also probes deeper into the relationships between innovation, living labs and geographical territories involved [1]. Another research goal is an 
impact evaluation, which goes beyond mere external opinions and points of view [19]. A model which ensures the continuity of the innovation process, which prevents common performance dropping is presented [20]. This model provides a technique and practical tools to this extent. It is a comprehensive model that supports, also visually, the general understanding of living labs to help fostering specific outcomes through participation of the relevant actors.

\subsection{Model design and description}

This practical oriented and functional model is similar to service-oriented architecture (SOA), which serves as a coordination and communication tool [21]. This model of serviceoriented structure requires a high degree of autonomy of the individual component, which can be integrated ad-hoc into the network and thereby interact with a large number of cooperation partners. Flexible adaptation within the network is possible even the dynamics, the elements and direction of interactions are changing.

"Accurate simulations typically require solutions of a nonlinear problem" [22], and accordingly are described with nonlinear equations. The in situ and real-life character of LL has to be agent or actor-based like in simulation models although it goes beyond simulation by concentrating on each active component of the system, whether it is an infrastructure, a method or an involved partner. This system can be a whole community or hotel, a single product or person, technical facilities, etc. For example alternating consumption of water in a hotel network is described by a system of non-linear equations [23], whereas solutions of nonlinear problems often require time-consuming and iterative techniques that sometimes do not converge. Therefore simplifications are often applied by linear approximations. Instead of previous, the use of agent-based network flow models without equations are necessary and acceptable. Using complex network models is justified, since they consider the interconnectivity and the interdependency of each component. On the component-level detailed information about influencing factors are necessary. In these complex network models, the key variables therefore, are defined by different colours and grouped by their character. The effect is depicted as a subsequent element or next level result and/or impact. The rules of interaction can be followed by the methodology and principles of LL and the characteristics and patterns of interaction can be decided on individual level of the actors of a system.

A further reduction in the complexity within the components is not possible because of the different functionalities of the model's components and because of different impacts of every single component to the results of the LL. There are no algorithms considered in this model, the concentration is on the description of components of the LL system (Figs 3 and 4), and on the network interdependencies (Figs 5 and 6) in order to provide a tool to create innovation.

A morphological analysis is conducted regarding how elements interact with each other, (Figs 5 and 6), to generate a whole system [24], in this case a living lab. Therefore a casebased scope addressing the interaction among a set of factors and stages of products and services, when analysing the entire sustainable tourism supply chain with its actors and interdependencies, is illustrated. The piers and pillars are demonstrating the functional flows, deriving originally from the network planning. The purpose is to move the causes and effects into the spotlight, realised herein by one or more directions of the arrows. The positive influence, according to the logic of "the more of one element, the more the effected element", and the same for "the less input variable, the less output variable" is applied in this model with the sign plus $(+)$. The negative cause-effect is demonstrated by "the more of one element, the less is the effected element" and the same for "the less input variable, the more 
output variable" is applied in this model with the sign minus (-). The layers and levels of interaction (Fig. 5), show all tiers of the supply chain, the directions, the collaboration partners, the dynamics and the frameworks, e.g. laws and regulations.

This approach supports the action research and can be tested in a real project by and for those taking action and thus is an appropriate approach. Action research means in this context, a methodology that can intertwine theory and practice on one side and the involvement of different stakeholders with distinct roles relevant in the situation, and highlight the importance of constant reflection [25].

\section{FINDINGS}

Essential findings about LL demonstrated in functional and flow models, such as the triangulation of LL and the key components of LL will be outlined. Based on these, the model of key components will be adapted to the whole travel and tourism sector (Fig. 3) and in a further model (Fig. 4) enhanced to hospitality businesses, concentrating on a hotel. Furthermore, the author detected that these models have to be developed, in order to give an in-depth understanding of the complexity of the hotel environment and has created a network model as a consequence of the existing lack of models for LL (Figs 5 and 6). The most important aspects will be characterized and discussed in the following.

\subsection{Evolution of existing living lab models}

Fig. 1 links the basic LL characteristics and their outcomes. At the same time it provides a framework to create a better understanding of the intended inputs and their contribution to the outcomes, and to reframe the innovation activities accordingly [2] with 11 key characteristics and three pillars. These characteristics are divided on a generic level, which is the LL environment and on a project level, which is the LL approach.

The Botnia model (Fig. 2) is defining the five key components of an ICT LL developed [3] adding to the triangulation model. The environment perspective, objects such as technological platforms and user communities are considered. With the methodology perspective, processes of data transfer and methods for user involvement are meant. The user

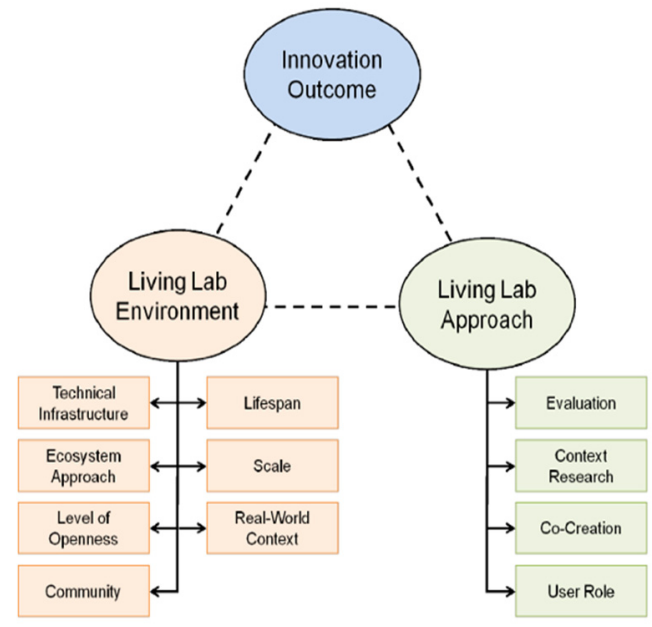

Figure 1: LL Triangulation between environment, approach and outcome in LL [9]. 


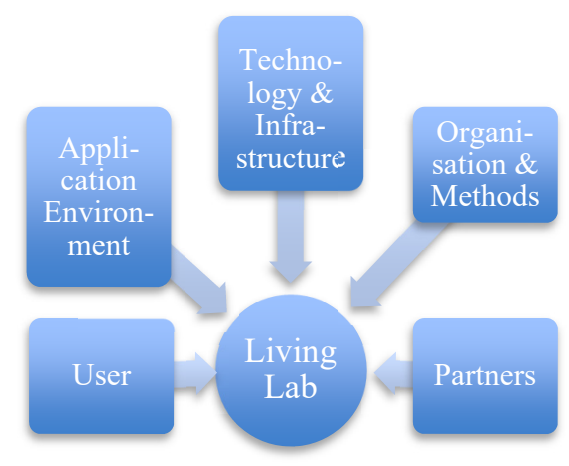

Figure 2: Key components of the Botnia LL. (Source: [3], adapted by author.)

comprises the end-users, the potential end-users and the co-creators. The application environment represents the context of user interaction and the reflection of the real world's usage scenarios. The technology and infrastructure component describes the role that existing and new technologies can play to facilitate new ways of cooperation and co-creating innovations with partners. Proposed standards and methods that emerge as best practices are included in organisation and methods. LL partners provide their own specific wealth of knowledge to collective intelligence and achieve subsequently higher standard of excellence.

Additionally, in relation to the above key components there are five key principles proposed in [27] as follows:

- Continuity - creativity and building trust takes time to develop

- Openness - many perspectives, open process to support whomever, wherever and whatever

- $\quad$ Realism - real-life setting

- Empowerment of users - engage and empower participation to generate valuable and sustainable assets

- Spontaneity - ability to aggregate and analyse spontaneous users' reactions

Three of these five key principles stand out. There is firstly empowerment, which is related to the user-centred and participatory design, secondly openness, related to open innovation and crowdsourcing, and thirdly the principle of realism, which focuses on the real-life setting of a LL and helps to facilitate as realistic use situations and behaviour as possible.

\subsection{Specifications and characteristics of existing models}

As a part of the entire LL, one major element within it, is the engagement of hotel guests, comprising former guests, active guests and potential guests (prospects). This spin-off to the guests can happen on following bases according to the concept of [27]: 1. Collaboration, e.g. through think-aloud observations, co-creativity workshops, innovation circles, 2. Transmission, e.g. by communicating knowledge to living lab initiators, to local community, on social media, to press releases, 3. Receiving, e.g. by collecting feedback of guests that stay in a resort, through surveys with former guests, interviews to expectations to a new hotel.

Stressing the importance of the user role, [2] systematically compiled different roles for incremental and radical innovations through living labs, such as the customizer, the 
fabricator, the designer and the inventor are specified. These user roles are linked to innovation outcomes by examining the role mechanisms associated to roles, e.g. the user making a proactive role to co-create radically new services, products, or processes together with a team and other LL actors, or the customizer that takes the roles of an informant, a tester and a contributor in incremental and stepwise innovations.

From an existing LL project, the SMART project, there are LL results delivered with three different intertwined purposes that are extracted as following [3]:

- To give facilitators the opportunity to engage citizens and user groups in their change, quality and innovation processes,

- To give citizens/individuals the opportunity to engage in innovation processes,

- To create opportunities for a dynamic region where boundary-crossing cooperation becomes usual in the change processes on all levels from product development to community building.

The levels of analysis for living labs detected in concurrent research are the macro, the meso and the micro level [28]. The macro level consists of the ecosystem which can be the whole destination in tourism with people-private-public partnership, whereas the meso level considers the space of encounter, the territorial dimension with a specific innovation project; in his study a hotel and resort, including the user-involvement, the co-creation and intervention [28]. The micro level can include the methodological steps of the LL as well as the spaces of encounter at a lower geographic level with close physical proximity, e.g. a collaborative space such as a co-creation workshop or an online creative ideas' generating tool [1].

\subsection{Further advancement and enhancement of models}

Fig. 3 comprises key actors of the general tourism living lab in detail and all key components described in 3.2 that are necessary for a user-centred and open innovation

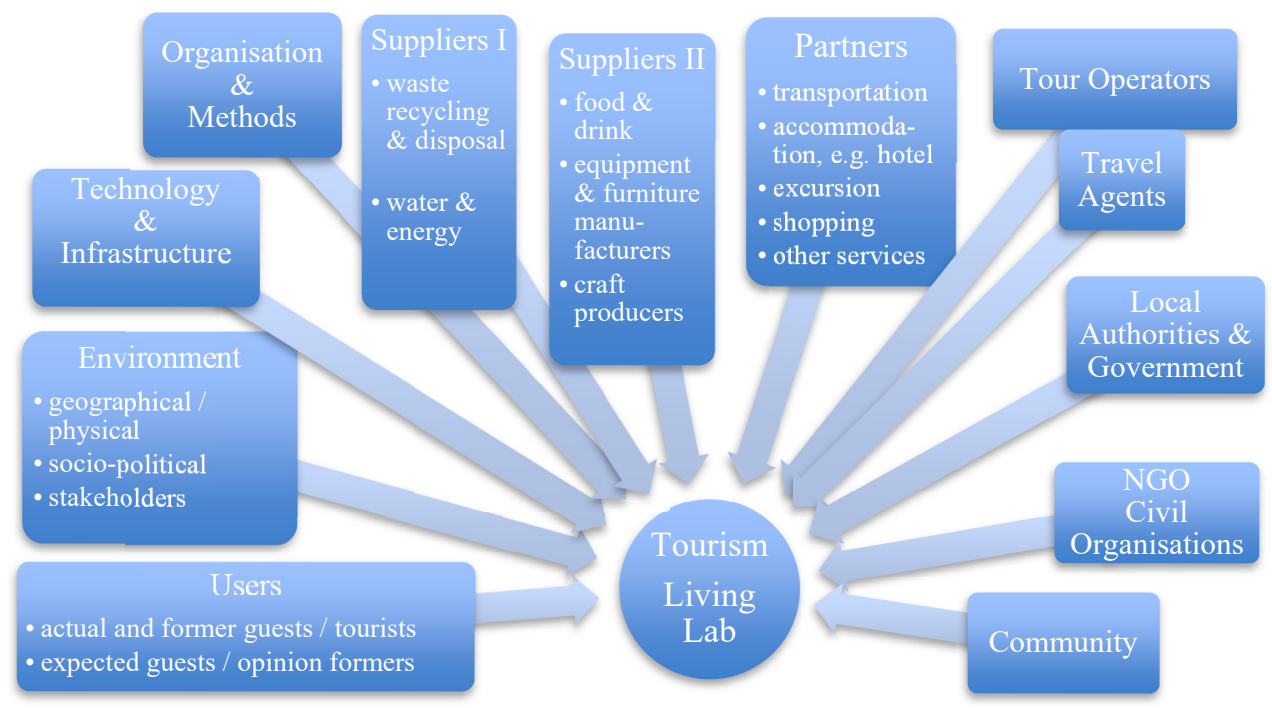

Figure 3: Key component of a Tourism Living Lab. (Source: authors' own presentation.) 
process. This model is enhanced by adding key actors of the entire tourism sector and the network partners.

The realm of environment and methodology, which are essential for the tourism living lab and its actors are embedded in the above model and described hereinafter.

- Users: Playing a key role as co-creators of the products, services and technologies being developed. Consideration of users' natural environment as tourists and in their daily routines. Involving ethnographic observation, empathy, and rapid real-life prototyping.

- Environment: Ecosystem of stakeholders who can interact to develop and assess products, services and processes, or systems. The physical or geographical region for in-situ approach. Socio-political and applications environment for the contextdriven approach. Milieu.

- Technology and Infrastructure: New or adjusted technologies to deliver benefits to users on all levels, e.g. facilitators and organisations, researchers, end-users. Set-up the base in the infrastructure to share opinions, knowledge and values, e.g. social media platforms, classic ICT. Provide hard- and software.

- Organisation and Methods: Action research, real-life setting, interaction of theory and practice. SMART goal setting and using key principles such as openness - on voluntary basis - to empower people, realism, comprising meetings and interviews with focus groups, in easily accessible places, and empowerment of users through participation, facilitating involvement, thus influencing key deliverables.

- Suppliers I: Mostly governmental or monopolistic providers: Water, Electricity, Gas, Solar, Photovoltaic, Wind and other Energy suppliers. Sewage, Drainage and Waste Management Systems providers with waste disposal and recycling. Many of them are run by state-affiliated companies or directly by municipalities.

- Suppliers II: Free market, choice: Food and drink manufacturers, equipment and furniture manufacturers, craft producers, and other services and products. Competitors to each other and/or cooperation partners.

- Partners: Different product and service providers: Access to means of transportation (rail, road, water, air), accommodation and excursion, e.g. hotel; and to separate shopping, dining or other entertainment activities. Access to intellectual property and all partners.

- Tour Operators: Combining travel components to natural, man-made and cultural heritages and attractions. Consulting travel agents, transportation and accommodation companies according to market needs.

- Travel Agents: Consult the client and sell all services and products to them.

- Local Authorities, Government: Laws, regulations, policies. Initiatives, e.g. destination marketing, access to all levels of tourism partners. Licensing.

- NGO, Civil Organisation and Civic Platforms: Public awareness, knowledge sharing, seals, protecting justice.

- Community: Sustained and meaningful interaction and community involvement, awareness. Participation in changes and growth of their physical environment.

Based on Zhang et al.'s [29] examined and identified tiers and relations within the tourism supply chain (TSC) and for the TSC, all the inter-related TSC members and integrated network partners are provided in this model. Arabska et al.'s [30] model of set up and functioning of a LL in integrated agriculture and tourist activities for sustainable development, containing NGO, Government and local authorities, and end-users is taken into 


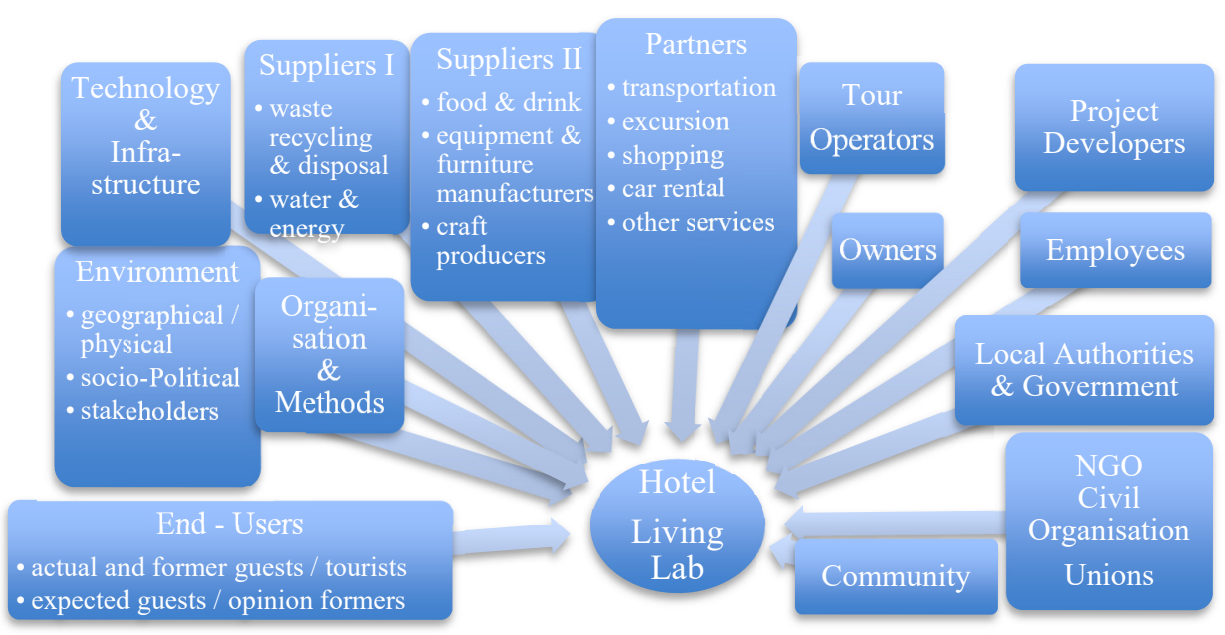

Figure 4: Key components of a hotel living lab. (Source: authors' own presentation.)

consideration and is completed by the author of this study. The entire environment for the tourism LL was inexistent in the academic research and literature so far, which is now available as visualisation and content-supported.

The organisation and their methods used is a good example to illustrate one of the following key components of a hotel LL.

Assuming that a management company with its General Manager, Department Heads and all rank and file employees, is running a hotel and having a hierarchical structure, will provide them with certain rights and duties. This functional and personal power allows them to act with the support of specific methods, such as an information management tool subsequently to foster a CSR target, e.g. ensuring a high quality of human rights and resources.

\subsection{Creation of new models}

The new models are taking the innovation targets into the centre of analysis. The first model in this section has a CSR outcome as target and in particular the engagement of suppliers, herein producers, transformers and end-users, with whom co-operation is of essential importance. The second model has targeted a sustainability outcome, in particular the engagement of users, herein implementers and end-users, with whom open innovation is a substantial condition.

Figs 5 and 6 are showing the innovation target or innovations outcome in the centre of the map, in the first case it is "the use of local suppliers with sustainable products, services and processes" (Fig. 5). The second innovation outcome (Fig. 6) is defined as "reduction of waste/clean surround", which is a real-life target for a TUI resort opening on Cape Verde [31]. Both models are mapping the key components, users and partners, organisation and methods, technology and infrastructure, methodology, application environment or ecosystem and taking the distinctive user roles [10] of informant, tester, contributor and co-creator into the models and thus in the entire research.

Model description: $\mathrm{S}=$ sourcing of products and services, $\mathrm{D}=$ delivery, $\mathrm{T}=$ transformation processes, $\mathrm{C} / \mathrm{P}=$ customers and product use, $\mathrm{VP}=$ value proposition, $\mathrm{OEM}=$ original equipment manufacturer, $3 \mathrm{R}=$ reuse, recycle, return [32]. 


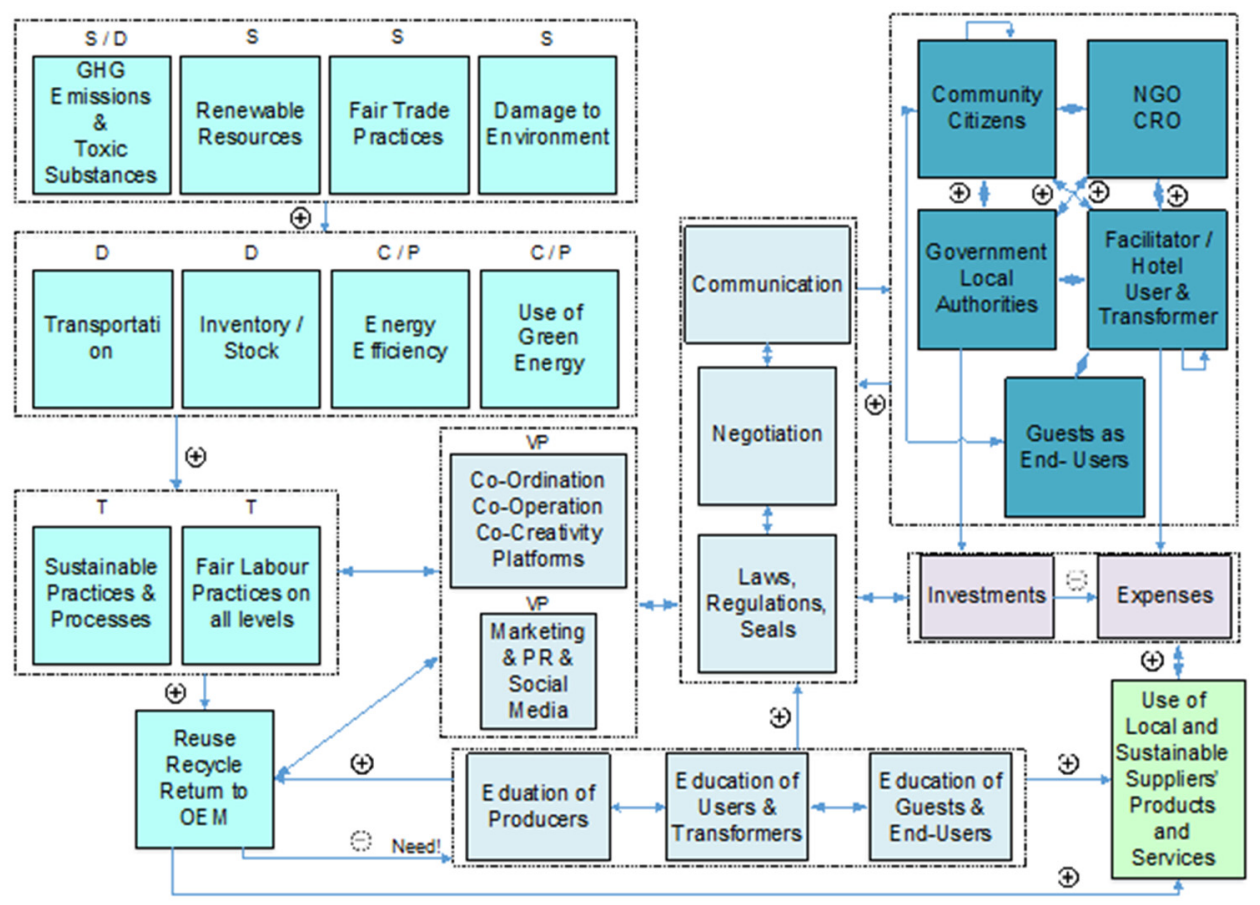

Figure 5: Network of interdependencies - fostering use of local and sustainable products. (Source: author.)

All issues for sustainable supply chain management (SSCM) are mapped on the left side of the above model and grouped by function similarities. In the top, sourcing and delivery functions, on the second level delivery and customers and products use, on the third level transformation aspects and the 3R to OEM as a key factor on the bottom, are illustrated.

Following the five key components of a living lab there are all users and partners mapped on the top right side of the model. The organisation and methods can be seen in the centre of the map describing value propositions such as co-ordination needs, co-operation and cocreativity needs and the necessity of providing the relevant platforms. At the same time communication, negotiations, available laws, regulations and seals used, represent a certain technology and infrastructure. The complete LL environment, containing further elements like marketing and PR for products and social media for user involvement, such as end-users or hotels as transformers, are vital elements for the methodology as well as application environment or ecosystem and the technology and infrastructure. The financial and economic aspects of facilitating a sustainable supply chain (SSC) lead to the question of investments or/and expenses required for the set-up of an operationalized LL involving the important partners such as owners, local authorities, pressure groups like community or nongovernmental and civil rights organisations. As another basic prerequisite for the successful and preceding factor the author concentrated on the education need of all producers, transformers and end-users. The successful implementation of a SSCM within a LL is dependent on the level of awareness, understanding of interdependencies and the fitness of its participants. The above and below flow models describe a process, that is changeable according to the assets and variables available. 


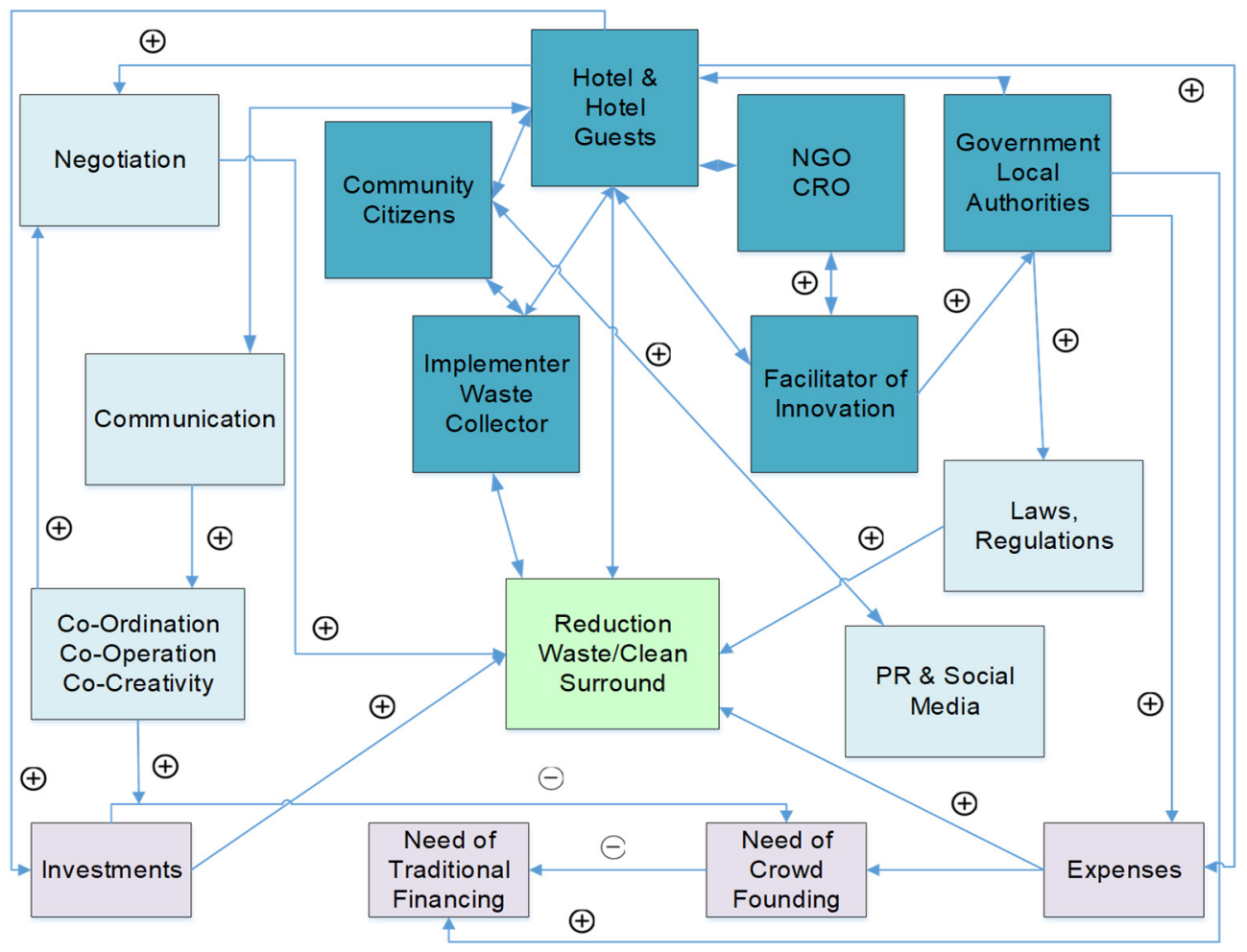

Figure 6: Network of interdependencies - waste reduction and removal with stakeholders. (Source: author.)

The above qualitative interdependency network models are in accordance to [33], [34] models developed; furthermore go beyond previous models by describing the LL on the meso level [1] and concentrating on the actual living lab project and its milieu. The last model created is reduced to key variables of the system, which can be changed according to dynamics, number and cause of elements, dimensions of it, or severity of the problem to be solved, interconnectedness, and adaptiveness and value for the involved actors.

\section{DISCUSSION}

The general discussion is about the approach, of open innovation versus closed innovation. There seem to be little doubt in the innovation capability of living labs. Academics agree on the standpoint that companies and governments have to provide the necessary environment and methodology to implement living labs, however there are very few hotels that are convinced by the best practices of other industries and that use benchmarks. The Accor chains' launch about open innovation can be considered as an early adopter of LL [35] in a significant and growing industry.

The generation of innovative ideas does not represent the problem of companies. According to [20], the innovation performance drops at every stage of the successive innovation chain and thus is one of the main problems of an innovation process. One main reason is the missing tool; another one is, that employees need training, concepts and techniques to innovate ultimately resulting in improvements. With these models, the author 
is providing a tool that can be categorized under the key component, method and organisation of a LL. Reducing the doubts in measurement of LL project outcomes, there are newest results published that verify the high performance of LL, measured by [36]. One reason of companies to hesitate to take over methodologies that seem reasonable to them is the one that perpetual motion is against their own frames of thinking and difficult to follow.

New own questions arise and have to be answered in further researches:

- If perpetual motion like in LL is against frames of thinking: How can scientists and practitioners overcome this barrier?

- How can further best practices and best methods and tools be provided to motivate the use of LL in tourism destinations and in touristic businesses?

- How can more methods and tools be provided to spur open innovation?

- How can companies be supported to measure their open innovation outcomes at every stage?

\section{CONCLUSION AND MANAGERIAL IMPLICATIONS}

In this paper, an approach for functional and network modelling of LL has been presented. The existing LL models and further developed ones for various sectors e.g. ICT by [37] as a methodology for the model driven development of service-oriented plant controls have been examined and enhanced (Figs 3 and 4).

The new models created by the author of this study, support the general understanding of the real world, which is done herein by visualisation. The network models describe interdependencies of the LL actors and the LL environment. Although it may theoretically be possible to model interdependencies within an open-innovation structure or system, substantial practical difficulties exist regarding system mapping. Problems can arise from the number of components and the number and dynamics of interaction and dependencies. Capturing the main functional characteristics of the system is one major function of herein created models, thus very useful and viable. The more accurate the system is described in terms of structure, dependencies, functions, the more it is perceived as a reliable model to understand and implement. The presented models are suited to grasp key elements, interactions and interdependencies. There is an understandably big fear of using methods and models that are unknown and unusual. The presented models in this paper are easily comprehensible for theorists and practitioners at the same time. It closes a gap of interdisciplinarity between different levels of action, between different sectors and between different scientific disciplines. By visualising complex interactions, the facilitators and actors of living lab can overcome the barrier of involving users into the development processes of systems as an enabler for generating common values and thus resulting in a better grasp on CSR and Sustainability. Adaptations to changing demands, e.g. stakeholders or relations, can be applied and thus swift transformation can be ensured.

Managers can use these models as tools for more intense co-creativity and interaction. By adopting existing models overcoming the barriers of involving users in development processes is much easier. It is not a contradiction to apply an easy-to-opt and elegant model and to show the whole complexity of the LL at the same time. Delivering value for all stakeholders is a prerequisite for the continuity in use of the model and in use of LL methodology and environment. A side effect is the immense image improvement and increase in brand value though state-of-the-art methods and tools. Whether intervention or redirection in roles, interdependencies or activities of the living lab are needed or not, can be analysed and explained by these models. 
Academics in literature about LL [3], [10], [11] are stressing the need of a shift of paradigm from producer-led innovation to user innovation. By showing the different roles of the user within the models, theorists and practitioners likewise can assign the activities of each stakeholder. These models created as new approaches can lead to new opportunities and comprehensive solutions. Surprising new areas and disruptive changes can be initiated. Bringing theory closer to practice closes another gap and is a fundamental need for new insights to a branch whose key factor of production is an intact nature. An intact world, comprising nature, social prosperity and peace are the key factors for the thriving of tourism and travel. Innovation by collaboration, co-creation and using collective intelligence to ultimately generate "inno-fusion" is a fundamental condition of qualitative growth and can be conducted by these orchestration models.

\section{REFERENCES}

[1] Guimont, D. \& Lapointe, D., Empowering local tourism providers to innovate through a living lab process. Technology Innovation Management Review, 6(11), pp. 18-25, 2016.

[2] Leminen, A., Nyström, A.-G. \& Westerlund, M., A typology of creative consumers in living labs. Journal of Technologies Engineering, 37, pp. 6-20, 2015.

[3] Bergvall-Kareborn, B. \& Stahlbrost, A., Living lab - an open and citizen-centric approach for innovation. International Journal of Innovation and Regional Development, 1(4), pp. 356-370, 2009.

[4] Rihova, I., Buhalis, D., Gouthro, M.B. \& Moital, M., Customer-to-customer cocreation practices in tourism: lessons from customer-dominant logic. Tourism Management, 67, pp. 362-375, 2018.

[5] Chiaroni, D., Chiasa, V. \& Frattini, F., Unravelling the process from closed to open innovation: evidence from mature, asset-intensive industries. Research \& Development Management, 40(3), pp. 222-245, 2010.

[6] Nyström, A.-G., Leminen, S., Westerlund, M. \& Kortelainen, M., Actor roles and role patterns influencing innovation in living labs. Industrial Marketing Management, 43(3), pp. 483-495, 2014.

[7] Mitchell, W.J., Me++: The Cyborg Self and the Networked City, MIT Press: Cambridge, 2003.

[8] Enoll. Online. http://enoll.org/about-us/. Accessed on: 23 Apr. 2018.

[9] Veeckman, C., Schuurman, D., Leminen, S. \& Westerlund, M., Linking living lab characteristics and their outcomes: towards a conceptual framework. Technology Innovation Management Review, pp. 6-15, 2013.

[10] Leminen, A., Nyström, A.-G. \& Westerlund, M., On becoming creative consumers. International Journal of Technology Marketing, 9(1), pp. 33-52, 2014.

[11] Lapointe, D., Guimont, D. \& Sévigny, A., The living lab approach to raise innovation capability among tourism practitioners. Tourism Dimension, 18, 2015.

[12] Schumpeter, J., Capitalism, Socialism and Democracy, Start Publishing LLC: New York, 2012, p. 83, 1942.

[13] Akenji, L., Consumer spacegoatism and limits to green consumerism. Journal of Cleaner Production, 63, pp.13-23, 2014.

[14] Kemp, R., Technology and the transition to environmental sustainability: the problem of technological regime shifts, futures. Procedia Engineering, 26, pp. 1023-1046, 1994. 
[15] Mabrouki, O., Amirat, Y., Chibani, M.V. \& De La Cruz, M.N., Context-aware framework for rural living labs. 19th International Conference on Software Engineering and Data Engineering, SEDE, pp. 146-151, 2010.

[16] Evans, P., Bristol Living Lab. Online: https://kwmc.org.uk/projects/bristollivinglab/. Accessed on: 20. Apr. 2018.

[17] [17] Leminen, S. \& Westerlund, M., Managing the challenges of becoming an open innovation company: experiences from living labs. Technology Innovation Management Review, 1(1), pp. 19-25, 2011.

[18] Collin, P., Notley, T. \& Third, A., Cultivating (digital) capacities: a role for social living labs? Digital Participation Through Social Living Labs, eds M. Dezuani, M. Foth, K. Mallan \& H. Hughes, Candos Publishing, pp. 19-36, 2018.

[19] Ballon, P., Van Hoed, M. \& Schuurman, D., The effectiveness of involving users in digital innovation: measuring the impact of living labs. Telematics and Informatics, 35(5), pp. 1021-1214. DOI: 10.1016/j.tele.2018.02.003.

[20] Birkinshaw, J., Bouquet, C. \& Barsoux, J.-L., The 5 myths of innovation: top 10 lessons on the new business innovation. MIT Sloan Management Review, pp. 1-8, 2011.

[21] James, F. \& Smith, H., Service-oriented paradigms in industrial automation. IEEE Transactions on Industrial Automatics, 1(1), 2005.

[22] Holden, R., Val, D.V., Burkhard, R. \& Nordwell, S., A network flow model for independent infrastructures at the local scale. Safety Science, 53, pp. 51-60, 2013.

[23] Wang, X.F., Song, Y. \& Irving, M., Modern Power Systems Analysis, Springer: New York.

[24] Bilge, P., Emec, S., Seliger, G. \& Jawahir, I.S., Mapping and integrating value creation factors with life-cycle stages for sustainable manufacturing. Procedia, The 24th CIRP Conference on Life Cycle Engineering, 61, pp. 28-33, 2017.

[25] Baskerville, R.L. \& Wood-Harper, T., A critical perspective on actin research as a method for information systems research. Journal of Information Technology, 11, pp. 235-246, 1996.

[26] CoreLabs, Living Labs Roadmap 2007-2010: Recommendations on Networked Systems for Open User-Driven Research, Development and Innovation, in Open Document, Luleå University of Technology, Centrum for Distance Spanning Technology: Luleå, 2007.

[27] Page, S.J., Hartwell, H., Johns, N., Fyall, A. \& Ladkin, A., Case study: wellness, tourism and small business development in a UK coastal resort: public engagement in practice. Tourism Management, 60, pp. 466-477, 2017.

[28] Schuurman, D., Bridging the gap between open and user innovation? Exploring the value of living labs as a means to structure user contribution and manage distributed innovation. Doctoral dissertation, Ghent University and Vrije Universiteit Brussel VUB, 2015.

[29] Zhang, X., Song, H. \& Huang, G., Tourism supply chain management: a new research agenda. Tourism Management, 30, pp. 345-358, 2009.

[30] Arabska, E., Shopova, I. \& Dimitrova, V., Living labs in integrated agriculture and tourism activities: driving innovations for sustainable rural development. The Malopolska School of Economics in Tarnow Research Papers Collection, 25(2), 2014.

[31] Hagspiel, T. Personal Communication, 18 April 2018, Head of Procurement and Sustainability, Robinson GmbH, TUI: Hannover. 
[32] Hassini, E., Chirag, S. \& Searcy, C., A literature review and a case study of sustainable supply chains with a focus on metrics. International Journal of Production Economics, 140, pp. 69-82, 2012.

[33] Vester, F., Die Kunst, vernetzt zu denken. Ideen und Werkzeuge für einen neuen Umgang mit Komplexität. München: dtv, 2002.

[34] Doerner, D., Die Logik des Misslingens. Strategisches Denken in komplexen Situationen, Reinbek: Rowohlt, pp. 1-372, 2003.

[35] Fontaine, F., How to build a collective intelligence ecosystem to innovate. In experts voice, from 20th Apr. 2018. Online. https://Tophotels.News/category/experts-voice/. Accessed on: 23 Apr. 2018.

[36] Schuurman, D., De Merez, L. \& Ballon, P. Living labs: a structured approach for implementing open and user innovation. Paper Presented at the 13th Annual Open and User Innovation Conference, Jul. 13, Lisbon, Portugal, 2015.

[37] Schmidt, J.-P., Müller, T. \& Weyrich, M., Methodology for the model driven development of service oriented plant controls. Procedia CIRP, 67, pp. 173-187, 2018. 